\title{
INFLAÇÃO VERSUS DESEMPREGO: NOVAS EVIDÊNCIAS PARA O BRASIL
}

\author{
Mário Jorge Cardoso de Mendonça * \\ Adolfo Sachsida ${ }^{+}$ \\ Luis Alberto Toscano Medrano $\ddagger$
}

\begin{abstract}
Resumo
O objetivo deste artigo é estimar a curva de Phillips novo-Keynesiana para o Brasil. Usamos diferentes proxies para variáveis e com amostras de diferentes períodos para checar a robustez do modelo. Os seguintes resultados merecem destaque. Primeiro, a expectativa inflação e a inflação passada têm relevância na dinâmica da inflação e sua importância das expectativas aumenta a partir de 2002. Segundo, o efeito do desemprego sobre a inflação parece estar localizado apenas no curto prazo. Por fim, parece haver uma quebra estrutural no efeito de uma mudança do câmbio sobre a inflação. Com dados a partir de 2002, o efeito de um choque cambial é negativo. Contudo, com a amostra desde 1995, o efeito de uma desvalorização cambial é positivo sobre a inflação.
\end{abstract}

Palavras-chave: Curva de Phillips; Inflação; Desemprego; Choque cambial; GMM-HAC.

\begin{abstract}
The goal of this article is to estimate the New Keynesian Phillips Curve for Brazil economy. The robustness was checking using not only different proxies but also samples with distinct temporal dimension. The main achievements are the following. Firstly, the inflationary inertia and expectation of inflation are important variables for the dynamic of inflation although the relevance of expectation rise from 2002 onwards. Secondly, the effect of unemployment on inflation seems to be located in the short term. Finally, the relationship between the exchange rate and inflation is marked by a structural break. With data from 2002, the effect of exchange rate shock is negative. But, when one uses data from 1995, the effect on inflation is positive impact.
\end{abstract}

Keywords: Phillips curve; Inflation; Rational expectations; Unemployment; Exchange rate shock; GMM-HAC method.

JEL classification: E31, E24, C33

\footnotetext{
* IPEA-Instituto de Pesquisa Econômica Aplicada. E-mail: mario.mendonca@hotmail.com

† IPEA-Instituto de Pesquisa Econômica Aplicada. E-mail: sachsida@hotmail.com

‡ IPEA-Instituto de Pesquisa Econômica Aplicada. E-mail: 1medrano10@msn.com
} 


\section{Introdução}

A história da curva de Phillips começou a partir de uma evidência empírica que se estendeu para a busca de uma explicação teórica. Especificamente, a curva de Phillips procura determinar se o aparente trade-off entre inflação e desemprego possui uma relação causal ou é somente uma correlação espúria. Originalmente, a curva de Phillips aparece num estudo de 1958 escrito por A. W. Phillips, que foi baseado em dados britânicos entre 1861 e 1957. Em Samuelson \& Solow (1960) argumentaram que essa relação poderia ser utilizada como ferramenta de política econômica. Se o governo quer reduzir o desemprego, isso poderia ser alcançado com o custo de alguma inflação através do uso de políticas fiscal e monetária expansionistas. Os dados para os Estados Unidos também pareciam mostrar que de fato existia um tradeoff entre inflação e desemprego.

Apesar desse aparente sucesso inicial, aconteceu uma significativa mudança de rumo no que se refere à percepção de que a curva de Phillips seja de fato uma regra consistente, na qual mais inflação poderia ser trocada por menos desemprego. Nos Estados Unidos, a inflação e o desemprego aumentaram ao mesmo tempo, criando a chamada "estagflação". Em 1975, a taxa de desemprego aumentou acentuadamente para 8,5\% ao ano, com a inflação atingindo picos em 1974 e 1975. Fato semelhante se repetiu no início de 1980 com o desemprego atingindo a marca de $9,7 \%$ ao ano e a inflação atingindo marcas elevadas entre 1979 e 1981. Tornou-se claro que uma taxa de inflação alta não garante uma taxa de desemprego baixa.

Uma equação análoga à curva de Phillips, mas aumentada pelas expectativas, compõe a base dos modelos de equilíbrio geral estocástico dinâmico mais recentes de cunho Novo Keynesiano. Nesses modelos com preços que não se alteram imediatamente, existe uma relação positiva entre a taxa de inflação e o nível do produto e, portanto uma relação negativa entre a taxa de inflação e a taxa de desemprego. Esta relação é denominada na literatura de "curva de Phillips novo keynesiana" (NKPC). ${ }^{1}$ A curva de Phillips novo keynesiana implica que a inflação crescente pode reduzir temporariamente o desemprego, mas não pode baixá-lo permanentemente. Dois trabalhos influentes que incorporam uma curva de Phillips novo keynesiana são Clarida et al. (1999) e Blanchard \& Galí (2007).

A moderna curva de Phillips novo-keynesiana se beneficiou das contribuições teóricas feitas por Clarida et al. (1999) e Svensson (2000). Contudo, na parte empírica existe considerável discussão sobre a importância da relação entre inflação e desemprego. Enquanto Galí \& Gertler (1999) — e Galí et al. (2001) - encontram evidências favoráveis à curva de Phillips, Rudd \& Whelan (2005) - Lindé (2005) e Bardsen et al. (2004) — mostram que a relevância empírica da curva de Phillips é questionável.

Para a economia brasileira, estudos recentes reativaram a polêmica sobre a adequação da curva de Phillips. Areosa et al. (2011) salientam a importância de modelos não lineares para explicar a evolução da dinâmica inflacionária brasileira. Eles concluem pela existência de dois regimes: o primeiro de baixa incerteza e o segundo de alta incerteza, sendo que a inércia inflacionária só seria relevante no regime de baixa incerteza (desaparecendo no regime de alta incerteza). Já o hiato do produto só seria significante quando a incerteza in-

\footnotetext{
${ }^{1}$ Do inglês New Keynesian Phillips Curve
} 
flacionária fosse alta. Isto é, a variável de custo marginal (hiato do produto nesse caso) teria habilidade para explicar a dinâmica inflacionária apenas em regimes de alta incerteza.

Sachsida (2009) estimam a curva de Phillips por meio de modelos não lineares, mostrando que os resultados são extremamente sensíveis tanto as proxies adotadas para representar o custo marginal das empresas, como também as especificações de linearidade adotadas.

Arruda et al. (2008) adotam modelos não lineares da Curva de Phillips para fins de previsão. Eles argumentam que a curva de Phillips ampliada com efeito limiar (threshold) é a que apresenta o melhor desempenho em termos preditivos. Segundo os autores, num regime com taxa de inflação de quatro meses abaixo de $0,17 \%$, o efeito da inércia inflacionária e do repasse cambial são estatisticamente insignificantes. Contudo, no regime em que a inflação dos quatro meses passados supera a marca de $0,17 \%$ os efeitos do repasse cambial, e da inércia inflacionária, aumentam e se tornam estatisticamente significantes. Mas, em ambos os casos, o hiato do produto não se mostrou estatisticamente significante.

Por outro lado, estimando a curva de Phillips para a economia brasileira, com dados trimestrais do período 1995:01 a 2008:04, Mazali \& Divino (2009) sugerem um bom grau de ajustamento da curva de Phillips aos dados brasileiros. Eles encontram os seguintes parâmetros, todos estatisticamente significantes: 0,59 para a inflação passada; 0,44 para a inflação futura; 0,06 para o choque cambial; e -0,13 para o desemprego.

Além destes estudos, vários outros autores têm pesquisado sobre a habilidade da curva de Phillips em descrever a dinâmica inflacionária nacional. Portugal et al. (1999), Lima (2003), Fasolo \& Portugal (2004), Muinhos (2004), Araujo \& e Guillén (2004), Alves \& Areosa (2005), Correa \& Minella (2005), Schwartzman (2006), entre outros, são alguns autores com importantes contribuições nessa área. ${ }^{2}$ A Tabela 1 abaixo mostra um breve apanhado de resultados para a economia brasileira.

O objetivo deste artigo é ampliar o conhecimento empírico de modo consistente acerca da curva de Phillips novo-Keynesiana para o Brasil. Para tal, utilizamos uma estratégia econométrica composta, não apenas pela escolha de métodos de estimação adequados, mas também da elaboração de uma investigação detalhada no que diz respeito à robustez dos resultados obtidos. Essa análise incluiu reestimar o modelo com base em diferentes variáveis proxies para a inflação e para a formação das expectativas assim como a aplicação de proxies das outras variáveis da NKPC, visando captar o efeito de cada uma nessa equação, uso de amostras dimensão temporal distintas, procedimentos para captar o efeito defasado de certas variáveis, entre outros. Isso nos possibilitou obter com certa segurança alguns resultados importantes. Entre os quais podemos destacar os seguintes.

Primeiro, a expectativa futura de inflação tem relevância na dinâmica do processo inflacionário. Contudo, o peso das expectativas apresenta maior importância que a inflação passada para amostra que começa a partir de 2002. Quando a amostra se estende com dados a partir de 1995, o efeito das expectativas é menor ou semelhante à inércia inflacionária. Segundo, podemos detectar com segurança que o desemprego tem impacto negativo sobre a inflação. Esse impacto negativo somente pode ser sentido no curto prazo. Para

\footnotetext{
${ }^{2}$ Sachsida (2009) fazem uma boa revisão da literatura sobre a curva de Phillips no Brasil.
} 


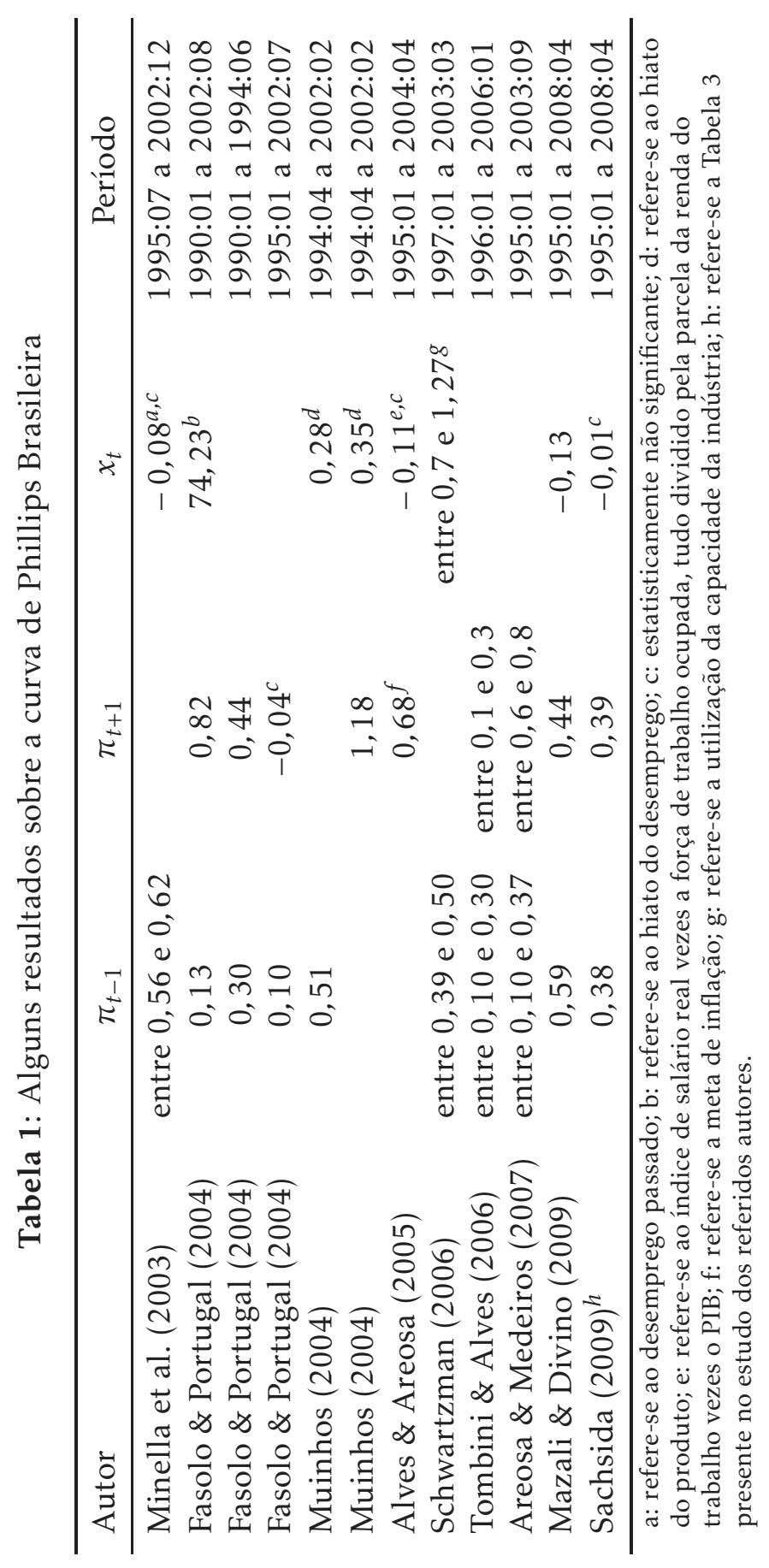


a amostra com dados desde 1995, esse efeito torna-se difícil de ser captado, dando a impressão de ser nulo ou pouco relevante na formação do processo inflacionário. Em terceiro lugar, no que diz respeito ao efeito de uma mudança do câmbio sobre a inflação, temos que novamente parece haver uma mudança estrutural no que tange ao efeito de um choque cambial sobre os preços. Novamente, para a amostra a partir de 2002, o efeito de um choque cambial é negativo. Isso implica dizer que uma desvalorização cambial ajuda a combater a inflação. Apesar de contra intuitivo, esse resultado não é novo na literatura. Tanto Kara \& Nelson (2002) como Allsopp et al. (2006) em estudos para o Reino Unido também encontram um efeito negativo do choque cambial. Diferentemente, com a amostra ampliada desde 1995, o efeito de uma desvalorização cambial é positivo sobre a inflação. Por fim, para a maior parte das regressões estimadas, não foi possível rejeitar a hipótese derivada da forma estrutural da NKCP de que a soma dos coeficientes da inflação passada e da expectativa de inflação seja igual à unidade.

Este estudo está estruturado da seguinte forma. Na seção 2 apresentamos as formas estrutural e reduzida da NKCP. Com base na forma estrutural, podem-se obter restrições sobre os valores de certos coeficientes a serem testadas econometricamente visando estabelecer se a regressão foi estimada de modo fidedigno. A seção 3 detalha a base de dados usada neste estudo. A estratégia econométrica que foi seguida é explicada na seção 4 . Os resultados econométricos são apresentados e analisados na seção 5. Por fim, as conclusões e comentários finais são postos na seção 6 .

\section{Modelo Econométrico}

A regressão a ser estimada para a economia brasileira está associada à seguinte equação:

$$
\pi_{t}=\beta_{1} \pi_{t-1}+\beta_{2} E_{t} \pi_{t+1}+\beta_{3} x_{t}+\beta_{4} z_{t}+\varepsilon_{t}
$$

onde $\pi_{t}$ é a taxa de inflação no período $t, E_{t} \pi_{t+1}=E\left[\pi_{t+1} \mid I_{t}\right]$ é a esperança matemática da taxa de inflação para o próximo $t+1$ formada com base no conjunto de informação $I_{t}, x_{t}$ é alguma variável que representa o custo marginal da empresa dentro da região $i, z_{t}$ é uma variável que representa um choque de oferta, e $\varepsilon_{t}$ é o erro que se assume ser independente e identicamente distribuído.

A forma reduzida representada pela equação (1) está associada forma estrutural a seguir derivada em Blanchard \& Galí (2007).

$$
\pi_{t}=\frac{1}{1+\beta} \pi_{t-1}+\frac{\beta}{1+\beta} E_{t} \pi_{t+1}-\frac{\lambda(1-\alpha)(1-\gamma) \phi}{\gamma(1+\beta)} x_{t}+\frac{\alpha \lambda}{1+\beta} z_{t}+\varepsilon_{t}
$$

onde $\beta \in(0,1)$ é o fator de desconto intertemporal, $\alpha \in(0,1)$ assinala que a função de produção da economia apresenta retorno constante de escala, $\lambda \equiv \theta^{-1}(1-\theta)(1-\beta \theta$ onde $\theta$ é fração das firmas que não reajustam o preço em cada período, $\gamma$ é o coeficiente que mede a rigidez salarial e $\phi$ indica a declividade da curva de oferta de trabalho. Tendo em vista a abordagem econométrica utilizada por Blanchard \& Galí (2007), bem como aquelas que serão empregadas neste estudo para estimar a equação (1), o único coeficiente estrutural que pode ser identificado é o fator de desconto $\beta$, o restante não pode 
ser recuperado. Baseado no fato de que $\beta \in(0,1)$, pode-se notar que a forma estrutural expressa por (2) impõe restrições sobre os parâmetros $\beta_{1}$ e $\beta_{2}$ da forma reduzida de modo que:

$$
\beta_{1}, \beta_{2} \in(0,1) \text { e } \beta_{1}+\beta_{2}=1
$$

\section{Base de Dados}

A escolha das proxies para essas variáveis não é trivial, e vários estudos escolhem diferentes conjuntos de variáveis, não havendo ainda uma metodologia que possa ser considerada a mais adequada para isso.

Como principal proxy representar a variável inflação adotamos a taxa de variação do IPCA ${ }^{3}$ (INFIPCA). A inflação medida pelo IPCA é a proxy padrão para os estudos que estimam a curva de Phillips brasileira após a implementação do regime de metas de inflação. De modo a perfazer uma análise de robustez, usaremos também outras proxies para a inflação e também para sua expectativa. Em relação às variáveis proxies para medir inflação, faremos uso de dois indicadores do núcleo ${ }^{4}$ da inflação e o IPC-FIPE. Para o núcleo da inflação, testamos o núcleo por exclusão (NÚCLEO1) que exclui do índice de inflação dez itens do subgrupo alimentação no domicílio e o item combustíveis e o núcleo por dupla ponderação ${ }^{5}$ (NÚCLEO2). Quanto à expectativa para inflação futura adotamos a duas medidas de previsão de inflação presentes no relatório FOCUS do Banco Central do Brasil. A primeira delas (FOCUSMD) é média tomada para todos os dias do mês da expectativa de inflação para o mês seguinte. A segunda (FOCUS30) é a expectativa do último dia do mês formada para o próximo mês. Em ambos os casos, tomou-se a mediana das previsões diárias obtidas das instituições financeiras que estão incluídas na pesquisa FOCUS. ${ }^{6}$

Para representar o custo marginal das empresas, variável $x$, adotamos a taxa de desemprego aberto de 30 dias (DESBR) que é divulgada pelo IBGE na Pesquisa Mensal de Emprego (PME). Também será testada usada como proxy para para o custo marginal das firmas a taxa de desemprego aberto para São Paulo (DESP) calculada pela Fundação SEADE/DIEESE .

O choque de oferta será representado aqui da mesma maneira que aparece em Mazali e Divino (2009), isto é, $z_{t}$ é medido pela mudança percentual na taxa de câmbio nominal real por dólar em relação a três períodos anteriores (CHOQUE3), de modo a captar o efeito defasado do choque cambial. Os dados referentes à taxa de câmbio foram obtidos junto ao Banco Central do Brasil. Formalmente temos que:

$$
z_{t}=\log \left[\frac{(R \$ / U S \$)_{t}}{(R \$ / U S \$)_{t-3}}\right]
$$

\footnotetext{
${ }^{3}$ Índice de Preços ao Consumidor Ampliado.

${ }^{4} \mathrm{O}$ objetivo de utilizar o núcleo é que este indicador atribui menor peso na composição do índice dos aumentos sazonais e circunstanciais. Essa metodologia de cálculo é utilizada para que se tenha o "real" comportamento da inflação. Desta forma, um aumento generalizado de preços na economia aparece no núcleo, mas um aumento localizado é excluído.

${ }^{5}$ De acordo com o Boletim de Inflação do Banco Central O critério utilizado para o cálculo desse indicador consiste na reponderação dos pesos originais - baseados na importância de cada item para a cesta do IPCA - pelos respectivos graus de volatilidade relativa, um procedimento que reduz a importância dos componentes mais voláteis.

${ }^{6}$ A pesquisa FOCUS começou a ser realizada em março de 2000.
} 
Também, faremos emprego de uma medida similar para esta variável cujo cálculo é feito em relação ao período anterior (CHOQUE1). A ideia é de que uma valorização cambial ao diminuir os preços dos insumos e produtos importados poderia arrefecer o aumento do índice de preços.

Embora a análise econométrica levada a cabo neste estudo utilize para efeito de análise de robustez amostras com dimensão temporal distinta, nosso modelo básico faz uso de dados mensais para o período 2002:01 a 2012:04. A escolha do período decorre basicamente de mudanças metodológicas adotadas pelo IBGE na série de desemprego, ${ }^{7}$ tornando essa série não comparável com valores anteriores. A série de desemprego para o Brasil, calculada pelo IBGE, sofreu alterações metodológicas. Sendo que a série antiga de desemprego foi interrompida em 2002, e a série nova de desemprego só foi calculada a partir de outubro de 2001. Dessa forma, em trabalhos anteriores, vários autores foram obrigados a adotar a taxa de desemprego de São Paulo, calculada pela Fundação SEADE em conjunto com o DIEESE, para representar a taxa de desemprego no Brasil. Este problema é certamente uma limitação importante dos trabalhos anteriores, afinal tal taxa de desemprego não necessariamente representa o Brasil como um todo. Naturalmente, espera-se que o sinal do coeficiente da taxa de desemprego na equação da curva de Phillips seja negativo.

Em relação à ordem de integração das variáveis, fica evidente que o curto intervalo de tempo disponível, menos de dez anos, torna comprometida a realização de testes de estacionaridade. De qualquer maneira, nos reportamos ao estudo de Mazali \& Divino (2009) que realizaram vários testes referentes à ordem de integração das séries inflação e desemprego, concluindo que ambas as variáveis são estacionárias na economia brasileira. Tais testes incluíram além dos tradicionais testes de ordem de integração, testes de ordem de integração com quebras estruturais. Os gráficos das variáveis descritas nesta seção estão no Apêndice Apêndice B e as Tabelas contendo suas estatísticas descritivas estão no Apêndice Apêndice A.

\section{Estratégia Econométrica}

Antes de passarmos para os resultados, façamos uma digressão acerca da estratégia econométrica definida como a sequência de métodos de estimação e testes adotados aqui para estimar a curva de Phillips, e checar se regressão está bem especificada. Usaremos aqui dois procedimentos econométricos para estimar a equação (1): o método de variáveis instrumentais (IV) e o método de momentos generalizados (GMM). O emprego do método de variáveis instrumentais para estimar esta equação (1) decorre do fato de que a expectativa acerca da inflação futura em $t+1$ é uma variável não observada. Definindo $\pi_{t+1}=E\left[\pi_{t+1} \mid I_{t}\right]+v_{t+1}$, onde $E\left[v_{t+1} \mid I_{t}=E\left[v_{t+1}\right]=0\right.$, temos que usando $\pi_{t+1}$ ao invés de $E\left[\pi_{t+1} \mid I_{t}\right]$, estaremos sujeitos à crítica relativa ao erro de medida caso a estimação seja feita por MQO. Outro modo de ver o uso do método IV é que na presença de expectativas racionais o erro $v_{t+1}$ deve ser ortogonal ao conjunto de informação $I_{t}$ no período $t$ e para um conjunto de variáveis $z_{t} \in I_{t}$. Assumindo por simplicidade que $\pi_{t}=\beta_{1} \pi_{t-1}+\beta_{2} E_{t} \pi_{t+1}+\varepsilon_{t}$, temos que a seguinte condição deve ser atendida

$$
E_{t}\left[\varepsilon_{t} z_{t}\right]=E_{t}\left[\left(\pi_{t}-\beta_{1} \pi_{t-1}-\beta_{2} \pi_{t+1}\right) z_{t}\right]=0
$$

\footnotetext{
${ }^{7}$ Esta série é calculada com base em dados de seis regiões metropolitanas.
} 
Embora muitos estudos utilizem a abordagem GMM para estimação de modelos com expectativas racionais, deve-se assinalar que esta metodologia não necessariamente é superior à estimação feita pelo método de variáveis instrumentais. De fato, Blanchard \& Galí (2007) usam o método IV para estimar a curva de Phillips Novo Keynesiana. Tal como ressalta Baum et al. (2007) numa excelente resenha acerca da aplicação dos métodos IV e GMM, a vantagem da abordagem GMM se dá, sobretudo, na presença de heteroscedasticidade. ${ }^{8}$ Ainda assim, tal vantagem em termos da propriedade de consistência do estimador GMM na presença de heteroscedasticidade pode ser ofuscada pelo custo de uma performance fraca para o caso de pequenas amostras. Deste modo, quando o problema de heteroscedasticidade não se faz presente, é preferível ainda o emprego do estimador de variáveis instrumentais. De modo a checar a existência de heteroscedasticidade na regressão, aplicamos neste estudo o uma versão específica do teste de Pagan \& Hall (1983). ${ }^{9}$ Aplicamos ainda o teste de Cumby \& Huizinga (1992) ${ }^{10}$ para testar a ocorrência de autocorrelação residual. Ambos os testes permanecem válidos na ocorrência de variável endógena na regressão.

Para que a aplicação do método IV seja adequada se faz necessário que os instrumentos sejam "bons instrumentos" no sentido de serem relevantes bem como válidos. No jargão econométrico isso significa que as variáveis usadas como instrumentos devam ser correlacionadas com os regressores endógenos e ao mesmo tempo ortogonais ao distúrbio da regressão. Neste sentido são mostrados na mesma Tabela o teste de sub-identificação. ${ }^{11}$ (Cragg \& Donald 1993, Kleibergen \& Paap 2006), ${ }^{12}$ o teste de sobre-identificação de SarganHansen, ${ }^{13}$ além do teste de Stock-Yogo (Stock \& Yogo 2005) para verificar se os instrumentos são fracos. ${ }^{14}$

A pesquisa teórica econométrica mais recente sobre o método de variáveis

\footnotetext{
${ }^{8}$ Embora na presença de heterocedasticidade a propriedade de consistência dos coeficientes estimados pelo método IV seja mantida, na estimação básica de variáveis instrumentais os erros padrão são inconsistentes e, portanto a inferência fica comprometida (Baum et al. 2007).

${ }^{9}$ Este teste assume a hipótese nula de homocedasticidade.

${ }^{10} \mathrm{~A}$ hipótese nula deste teste é de não autocorrelação residual.

${ }^{11}$ Para que uma equação seja identificada no modelo IV tanto a condição de ordem $(L \geqslant K)$, onde $L$ é o número de variáveis instrumentais e $K$ o número de regressores, como a condição de posto devem ser preenchidas. Esta última assinala que $Q x z=E\left(X^{\prime} Z\right)$ deve ser de posto completo, onde $X=(X 1, X 2)=$ (Endógenas, Exógenas) é a matriz de regressores, enquanto $Z=(Z 1, Z 2)=$ (Exclusos, Inclusos) é a matriz dos instrumentos, sendo $Z 2=X 2$. Quando isso não ocorre dizemos que o modelo é sub-identificado ou não identificado. Pode-se testar a condição de posto por meio do teste de Cragg \& Donald (1993), cuja não rejeição da hipótese nula sugere que o modelo é sub-identificado.

${ }^{12} \mathrm{Na}$ presença de heteroscedasticidade e autocorrelação residual, a estatística de CraggDonald não mais permanece válida. Em tais circunstâncias, o teste de Kleibergen \& Paap (2006) será usado como alternativa ao teste Cragg \& Donald (1993) quando as circunstâncias assim exigirem.

${ }^{13} \mathrm{~A}$ independência do instrumento com relação ao distúrbio somente pode ser acessada se, e somente se, houver uma "abundância" de instrumentos, isto é, se a equação é sobre-identificada. Isto se dá quando a condição de ordem é satisfeita na desigualdade: o número de instrumentos excluídos é superior ao regressores endógenos. O teste de Sargan-Hansen é usado para testar a hipótese de sobre-identificação. Sob a hipótese nula os instrumentos são válidos, ou seja, não correlacionados com o distúrbio. Sob ainda esta hipótese, a estatística de teste tem distribuição qui-quadrado com $L-K$ restrições sobre-identificadas.

${ }^{14}$ Instrumentos que explicam pouco a variação da variável explicativa endógena (fraca correlação entre $Z$ e $X$ ) são considerados instrumentos fracos. O teste de Stock-Yogo (Stock \& Yogo 2005) é calculado com base na estatística $F$ de Cragg \& Donald (1993). Sob a hipótese nula o estimador é fracamente identificado no sentido de que o viés verificado é inaceitavelmente grande.
} 
instrumentais tem enfatizado muito a questão dos instrumentos fracos (Stock et al. 2002, Moreira 2003, Stock \& Yogo 2005). Ma (2002) aponta que o uso de instrumentos pode ser um sério problema nos estudos para a curva de Phillips Novo-Keynesiana. Quando os instrumentos são fracos, dois problemas sérios ocorrem na estimação por dois estágios (2SLS). O primeiro é a questão do viés. Embora o método 2 SLS seja consistente, ${ }^{15}$ as estimativas são sempre viesadas para pequenas amostras. Segundo, quando os instrumentos são fracos, o erro padrão estimado torna-se muito pequeno. Neste caso, o intervalo de confiança é não fidedigno, pois juntamente ao fato de que o ponto médio deste estimador ser viesado, temos que o intervalo de confiança tornase pequeno. Isso tudo faz com que o procedimento de teste de hipótese na estimação por 2SLS fragilize-se no caso da ocorrência de instrumentos fracos. Como Staiger e Stock mostraram que o problema de instrumentos fracos pode ocorrer mesmo se no primeiro estágio, os testes são significativos nos níveis convencionais ( $5 \%$ ou $10 \%$ ) e para grandes amostras.

Vários testes são sugeridos na literatura para testar a hipótese de instrumentos fracos. Uma estatística comumente usada é o $R^{2}$ do primeiro estágio com os instrumentos dito "inclusos" a (Bound et al. 1995). ${ }^{16}$ Contudo, quando existe mais de uma variável endógena na regressão, esse indicador pode não ser mais válido. Shea (1997) propôs uma estatística conhecida como "R2 parcial" que capta a intercorrelação entre os instrumentos. Quando somente existe uma variável endógenas, as duas medidas de $R^{2}$ são equivalentes. Outra regra aplicada quando se tem apenas um regressor endógeno é checar se o valor da estatística F no primeiro estágio. Nesse caso, um valor menor que 10 pode ser uma indicação que os instrumentos são fracos. Alternativamente Stock \& Yogo (2005) sugerem um teste onde a hipótese nula é que o viés do estimador 2SLS seja menor que uma fração (digamos, 10\%) do estimador OLS. ${ }^{17}$ De acordo com Murray (2006) a mais recente abordagem em relação ao problema de teste de hipótese com instrumentos fracos e um único regressor endógeno é o "teste da razão de verossimilhança condicional", desenvolvido por Moreira (2003) e aperfeiçoado em Andrews et al. (2006) e Andrews \& Stock (2005). O teste de Moreira (2003) supera as distorções encontradas nos testes convencionais ajustando os valores críticos do teste de hipótese de acordo com cada amostra, de modo que o intervalo de confiança corrigido gere um nível de significância correto. Assim, seus valores críticos "são condicionados" nos dados à disposição e não constante.

\section{Resultados Econométricos}

Passemos agora à análise dos resultados econométricos obtidos para a curva de Phillips Novo Keynesiana. A Tabela 2 mostra os resultados da estimação da curva de Phillips utilizando dados de séries de tempo para o período entre jan/2002 e mar/2012. A inflação aqui é medida pela taxa de variação do IPCA.

\footnotetext{
${ }^{15}$ De modo que quase certamente o valor médio do estimador 2SLS se aproxima do verdadeiro valor do parâmetro quando o tamanho da amostra convirja para o infinito.

${ }^{16}$ Alternativamente, isso também pode ser expresso como um teste F da significância conjunta dos instrumentos exclusos Z1.

${ }^{17} \mathrm{O}$ teste de Stock-Yogo (Stock \& Yogo 2005) não mais recai na estatística $F$ que comumente aparece na prática econométrica, mas numa generalização da estatística de Cragg-Donald. Os valores críticos deste teste são obtidos a partir de uma distribuição não padrão.
} 
Testamos aqui três conjuntos de variáveis instrumentais para instrumentalizar a taxa de inflação em $t+1$ (EXPINFIPCA) definidos da seguinte forma:

C1 incluí as defasagens até a terceira ordem da inflação, desemprego e choque cambial;

C2 incluiu além das varáveis do conjunto C1, a taxa Selic com as mesmas ordens de defasagens; e

C3 adiciona ao conjunto C2, o índice de preço de commodities. ${ }^{18}$

Sims (1992) sugere o uso de um índice de preço de commodities na estimação do VAR estrutural como meio de eliminar o chamado "price puzzle", 19 pois essa variável carregaria informação quanto ao comportamento da inflação futura. Sendo assim, o Banco Central poderia fazer uso desse indicador para formar sua expectativa quanto à inflação futura.

Com relação aos resultados da Tabela 2, podemos inicialmente fazer os seguintes comentários. Aqui a constante não foi incluída na regressão. A exclusão da constante na estimação da NKPC é padrão nos estudos relacionados e está em conformidade com a forma estrutural que aparece na equação (1). Nas colunas 1-3, tal como aparece Blanchard \& Galí (2007), o modelo foi estimado pelo método IV. Com relação aos resultados que aparecem nas colunas 1-3, os testes de Pagan-Hall e Cumby-Huizinga indicam, respectivamente, ocorrência de heteroscedasticidade e autocorrelação nos resíduos. Também os resultados obtidos para as regressões dessas três colunas, apontam para o fato de que, de acordo com o teste de sub-identificação, a condição de ordem não foi atendida. Quanto ao sinal dos coeficientes, temos que a expectativa de inflação futura (EINFIPCA) e inflação defasada (L1INFIPCA) se mostram significativas com os sinais esperados, enquanto que taxa de desemprego (DESBR) e ao choque cambial (CHOQUE3) não são significativos e além de tudo, com sinais contrários ao esperado.

No que se refere ainda aos resultados das colunas 1-3, alguns pontos merecem ser ressaltados. Primeiro, de acordo com as estatísticas para verificar a capacidade dos instrumentos ( $R^{2}$ parcial, F-teste e o teste Stock-Yogo), somente o conjunto $\mathrm{C} 3$ de instrumentos que incluiu o índice de commodities está apto a preencher a condição de "bons instrumentos". Isso significa que o índice de commodities é de fato um bom preditor para a inflação. Segundo, em nenhum caso rejeita-se a hipótese de que a soma dos coeficientes da inflação passada com a expectativa da inflação futura seja igual à unidade.

Tendo em vista a presença de alguns problemas importantes de especificação na estimação pelo método IV, sobretudo no que se refere ao problema de heteroscedasticidade, o exercício seguinte se dá pela estimação da NKPK por método GMM. As estimativas aqui são ditas GMM-HAC ${ }^{20}$ (Baum et al. 2007), pois os estimadores são consistentes na presença de autocorrelação e heteroscedasticidade (colunas 4 e 5). Nesta especificação, os testes de Sargan-Hansen e de sub-identificação apontam para o fato de que a condição de ordem é atendida, e o teste de Stock-Yogo rejeita a hipótese de que os instrumentos são

\footnotetext{
${ }^{18}$ Esta começa a ser elaborada pelo Banco Central do Brasil em março de 1998.

${ }^{19} \mathrm{O}$ que pode ser traduzido como 'quebra cabeça dos preços'.

${ }^{20} \mathrm{HAC}$ é um acronimo para 'heterosdasticity and autocorrelation consistent'.
} 
fracos, mas a condição de posto, verificada pelo teste de sub-identificação, não é satisfeita. ${ }^{21}$

Em relação aos coeficientes estimados e que aparecem nas colunas (4) e (5) temos que as variáveis EINFIPCA e L1INFIPCA se mostram, tal como na estimação por método IV, significativas com os sinais esperados. Entretanto observamos que a expectativa possui maior peso que a inflação passada no processo inflacionário. Importante ressaltar que na estimação corrigida por GMM-HAC, a taxa de desemprego é significativa e com sinal negativo, tal como esperado. Contudo, o impacto desta variável sobre a inflação é pouco relevante. Para se ter uma ideia, vejamos qual seria o efeito sobre a inflação decorrente do aumento de um ponto percentual da taxa de desemprego. No Apêndice $B$, verifica-se que a taxa média mensal do desemprego no período de jan/02 a mar/12 foi de $9.18 \%$. Tomando como parâmetro os resultados da coluna (6) da Tabela 1 teríamos que o aumento de um ponto percentual teria apenas um efeito negativo de 0,004 ponto percentual na taxa de inflação mensal predita ou de 0,04 ponto percentual na taxa anual de inflação projetada.

No caso do choque cambial, a variável CHOQUE3 mostra-se agora como significativa, mas mantém o sinal negativo em desacordo com o esperado. De modo a testar a robustez desse resultado, na coluna (5) usamos a variável CHOQUE1 que mede a variação cambial em relação somente ao período anterior. Observa-se, contudo, que o resultado manteve-se qualitativamente o mesmo. Por fim, a hipótese de soma igual à unidade dos coeficientes das variáveis EINFIPCA e L1INFIPCA não foi rejeitada.

De modo a testar a robustez dos resultados alcançados na Tabela 2, a seguir usamos diferentes proxies para a taxa de inflação como o IPC-FIPE e duas medidas para o núcleo da inflação, NUCLEO1 e NUCLEO2. Os resultados aparecem na Tabela 3. Usamos ainda em todas as estimações o conjunto C3 de variáveis instrumentais para instrumentalizar a inflação futura. Inicialmente, na coluna (1) usamos o IPC-FIPE enquanto naturalmente usamos a variável DESSP como proxy para o desemprego. A estimação aqui feita usando o método IV. Tal como pode ser visto na coluna (1), os mesmos problemas de especificação quanto à presença de heteroscedasticidade e autocorrelação são registrados, tal como nos casos anteriores das regressões por método IV que aparecem na Tabela 2. Do mesmo modo, a taxa de desemprego aparece com sinal negativo e não estatisticamente significativa. O mesmo ocorrendo para o choque cambial. Contudo, as variáveis EINFIPC e L1INFIPC são significativas, com a expectativa de inflação sendo dominante para explicar a dinâmica inflacionária brasileira.

Na coluna (2), refazemos a estimação da coluna anterior por método GMMHAC. Conforme pode ser visto, uma vez corrigido o problema de especificação, os resultados obtidos mostram que a taxa de desemprego é significativa com o sinal esperado enquanto o choque cambial não apresenta significância estatística, mas tal como no caso anterior preserva o sinal negativo. A seguir, nas colunas (3) e (4) estimamos igualmente a curva de Phillips NK, empregando duas medidas de núcleo da inflação, respectivamente, NUCLEO2 E NUCLEO1. Conforme pode ser visto, com a variável NUCLEO2, na regressão que aparece na coluna (3), a taxa de desemprego é significativa e com sinal negativo tal como esperado. No caso do choque cambial, a variável CHOQUE3

\footnotetext{
${ }^{21}$ Este problema desaparece quando estimamos a mesma regressão sem correção de heterocedasticidade.
} 


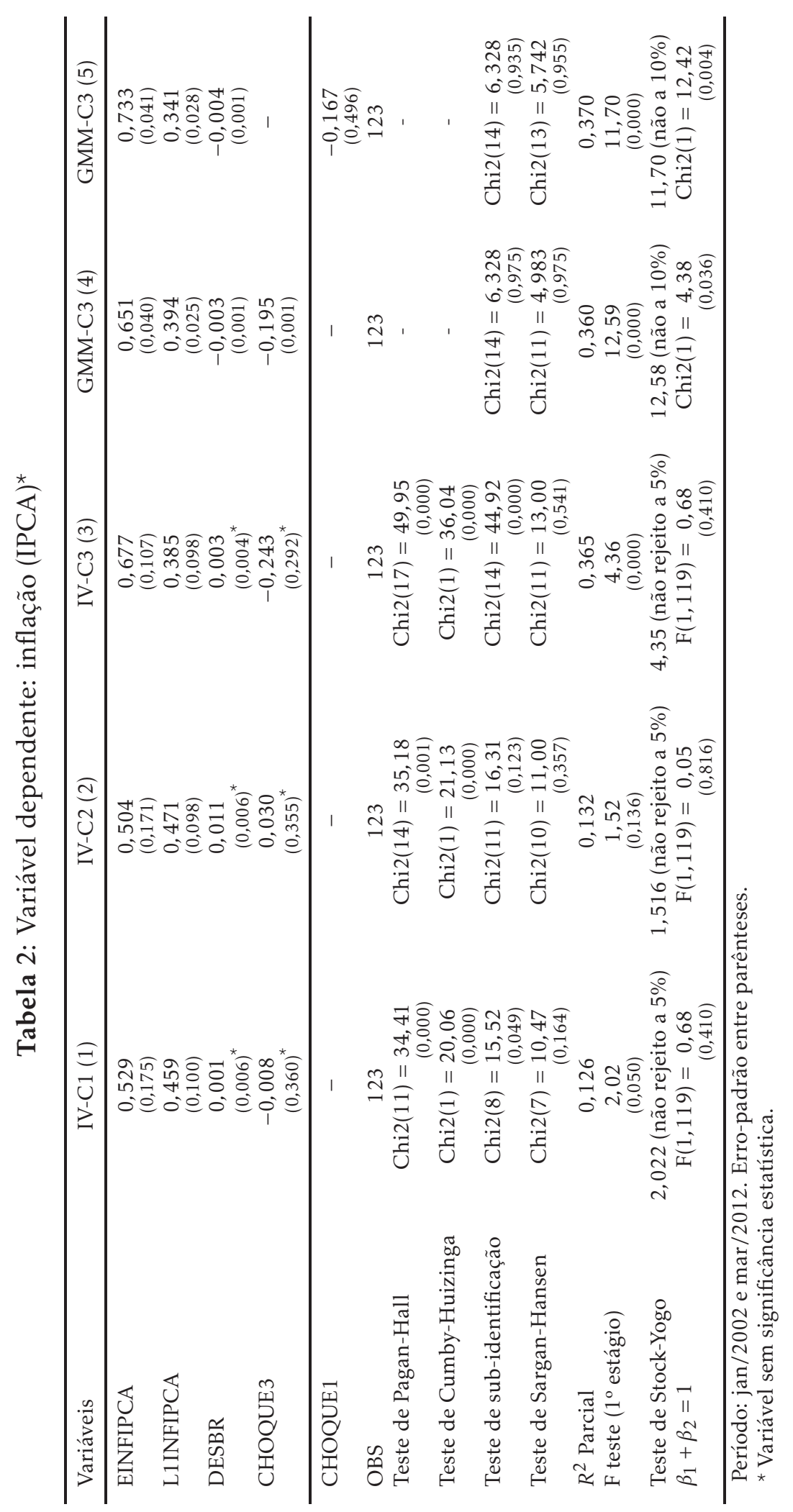


é significativa, entretanto mantém o sinal intrigante. Contudo, na regressão que usa como proxy para inflação a variável NUCLEO1, coluna (4), a taxa de desemprego perde significância enquanto a variável choque cambial se mostra ainda significativa e com sinal negativo.

Nas duas últimas colunas da Tabela 3, diferentemente dos exercícios anteriores, usamos desta vez duas variáveis proxies para expectativa de inflação geradas a partir da pesquisa Focus realizada pelo Banco Central. A média das expectativas diárias para o mês seguinte (FOCUSMD) e expectativa obtida do último dia do mês (FOCUS30). ${ }^{22}$ Conforme pode ser visto, embora em ambos os casos o coeficiente relativo à expectativa futura seja similar aos das outras colunas dessa tabela, verifica-se nas colunas (5) e (6) que o impacto da inflação passada aumenta de importância. No caso da regressão da coluna (5) onde a variável FOCUSMD foi usada, a taxa de desemprego é significativa com sinal esperado, enquanto que quando se estima a regressão com a variável FOCUS30, a taxa de desemprego deixa de ser significativa. Contudo, essa perda de significância estatística não é assim tão acentuada. Intrigante aqui é que nas regressões das colunas (5) e (6), o choque cambial, representado pela variável CHOQUE3, é significativo apresentando desta vez o sinal esperado.

Por fim, nas regressões que aparecem nas colunas (2) e (6), os testes de Sargan/Hansen e de sub-identificação assinalam que as condições de ordem e de posto são atendidas, enquanto o teste de Stock-Yogo e o teste F rejeitam a hipótese nula de que os instrumentos são fracos ao nível de significância de 5Em relação à hipótese de soma igual à unidade dos coeficientes das variáveis EINFIPCA e L1INFIPCA, os testes não são conclusivos para os resultados das regressões estimadas na Tabela 3.

O último exercício de robustez da análise econométrica acerca da estimação da NKCP baseia-se na estimação dessa equação com base e uma amostra de tamanho ampliado. Os dados amostrais agora estendem-se de jan/1995 a mar/12. É oportuno ressaltar que em relação às variáveis explicativas não poderemos lançar mão da taxa de desemprego calculada pelo IBGE calculada para o Brasil pelos motivos apontados na seção III. Pelo fato de que a taxa de desemprego aberto para a região metropolitana de São Paulo (DESP) estar disponível para esse período, uma alternativa foi usar o IPC-FIPE como proxy para a inflação nesse período. Temos ainda o índice de preço de commodities, que mostrou-se ser um importante preditor para a expectativa de inflação, não pode aqui ser mais utilizada como variável instrumental pelo fato de que este indicador somente começa a ser apurado a partir de março de 2000. Substituímos essa variável pelo hiato da produção industrial. ${ }^{23}$ Assim, faremos uso de um novo conjunto de variáveis instrumentais $\mathrm{C} 4$, definido da seguinte forma:

C4 incluí as defasagens até a terceira ordem da inflação, desemprego, choque cambial, da taxa Selic, e do hiato do produto industrial.

As regressões estimadas usando o conjunto de variáveis instrumentais C4 são mostradas na Tabela 4. Na coluna (1), estimamos a NKPC pelo método de variáveis instrumentais. Conforme pode ser visto, temos aqui os problemas usuais de especificação quanto à presença de heteroscedasticidade e autocorrelação serial, assim como os problemas de identificação detectados nas esti-

\footnotetext{
${ }^{22}$ Para maiores detalhes, ver seção 3.

${ }^{23}$ Desvio em relação à tendência do produto industrial calculado pelo filtro de HodrickPrescott.
} 


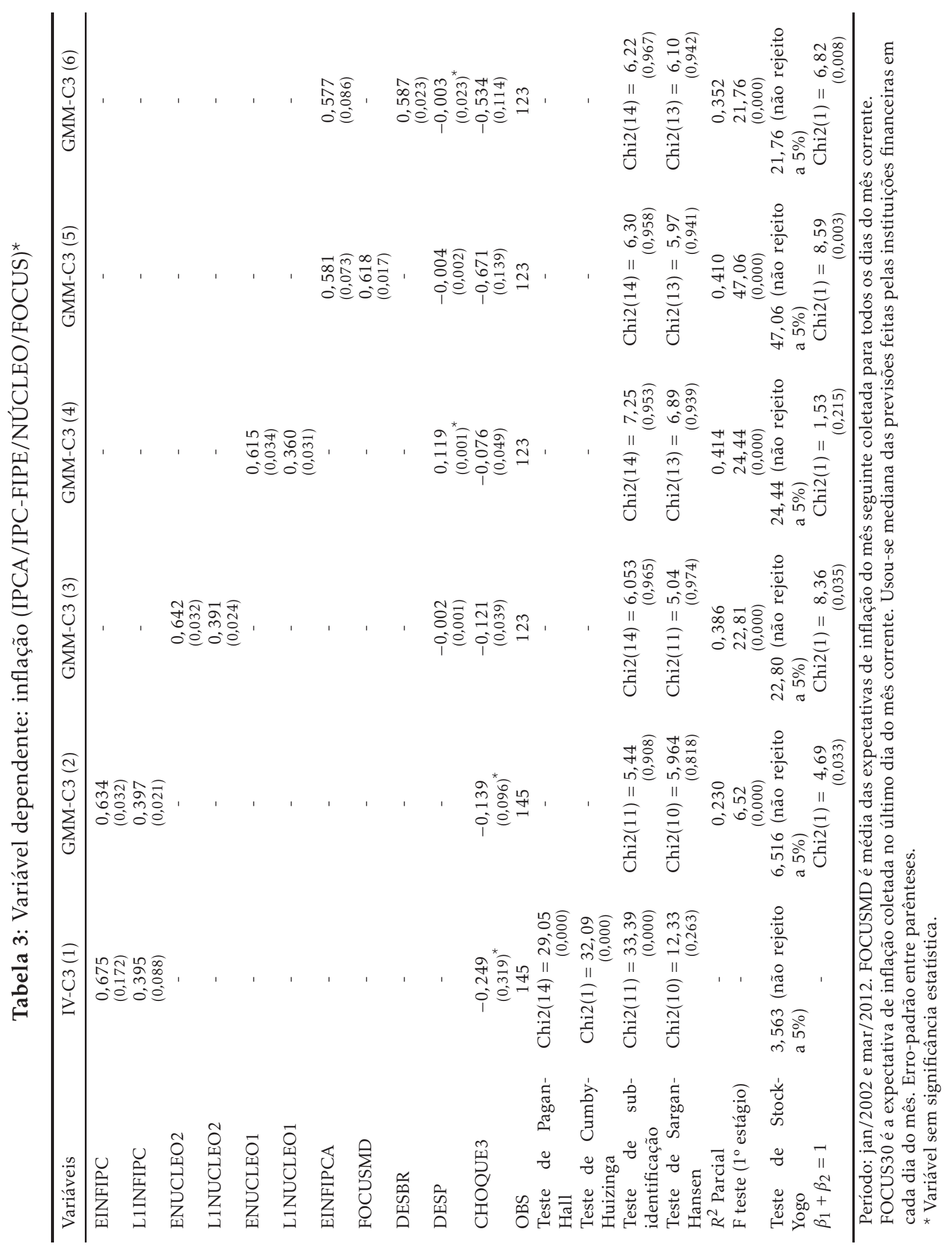


mações feitas até aqui que fazem uso do método IV. No que se refere ao sinal dos coeficientes, temos que apenas a inflação defasada mostrou-se significativa.

Na coluna (2), corrigimos os problemas da regressão anterior pelo método GMM-HAC. Neste caso, alguns resultados interessantes novamente voltam a se configurar. Temos então agora que a expectativa de inflação (EINFIPC) e inflação defasada (L1INFIPC) são ambas significativas. Contudo, o valor do coeficiente de EINFIPC diminui consideravelmente em relação às estimativas que aparecem nas Tabelas 2 e 3. Intrigante ainda é o que acontece com a taxa de desemprego (DESP) que embora seja significativa, apresenta sinal contrário ao esperado. Sobre a dinâmica do desemprego, Estevão \& Carvalho Filho (2012) fornecem maiores detalhes sobre os efeitos da Constituição de 1988, e da adoção do regime de metas de inflação, sobre a elasticidade dos salários reais em relação à taxa de desemprego. Os autores sugerem que a introdução do regime de metas de inflação aumentou a inclinação da curva entre salários reais e desemprego. Isto é, após a adoção do regime de metas, os salários passaram a responder mais aos fundamentos do mercado de trabalho. Com relação ao choque cambial, temos um resultado mais animador. A variável CHOQUE3 não apenas se mostra significativa como apresenta o sinal esperado.

Com intuito de investigar o real efeito do desemprego e também do choque cambial na estimação da curva de Phillips, na coluna (3) as variáveis DESP e CHOQUE3 entram na regressão nas defasagens até terceira ordem. Os resultados obtidos mostram que no caso da variável DESP, as defasagens parecem importar, pois todas são significativas. Além disso, o teste de Wald rejeita a hipótese nula de que a soma dos coeficientes é igual à zero. ${ }^{24}$ Com relação à variável CHOQUE3, temos que apenas a defasagem de ordem um é significativa e com sinal positivo. Repetimos na coluna (4), o mesmo exercício da coluna (3) exceto pelo fato de que usamos a variável CHOQUE1 como proxy para o choque de oferta. Observa-se, entretanto, que não ocorreu mudança significativa nos resultados.

Para aprofundarmos nossa investigação, usaremos nas regressões das colunas (5) e (6) outra variável como proxy para representar o desemprego, que agora será representado pelo hiato ou desvio da taxa de desemprego (HDESP) em relação a sua tendência. ${ }^{25} \mathrm{Na}$ regressão da coluna (5), temos que quando essa variável é usada no nível, o sinal do coeficiente obtido é o esperado embora sem significância estatística. Contudo, a variável CHOQUE3 mantém-se significativa, com o sinal esperado. Na última coluna da Tabela 4, introduzimos as defasagens até terceira ordem da variável HDESP. Observa-se neste caso que tal como foi visto nas regressões estimadas das colunas (3) e (4), todas as defasagens usadas são significativas. Entretanto o teste de Wald não rejeita a hipótese nula de que a soma dos coeficientes é igual à zero. ${ }^{26}$ Para a variável CHOQUE3, tal como nos casos anteriores, somente a primeira defasagem foi significativa, sendo o sinal obtido também em conformidade com o esperado.

Vale comentar que em todos os casos das regressões estimadas pelo método GMM-HAC, os testes assinalam que as condições de ordem e de posto são

\footnotetext{
${ }^{24}$ Teste de Wald: $\operatorname{Chi}(1)=11,23$.

$(0,000)$

${ }^{25}$ Tendência estimada a partir da aplicação do filtro de Hodrick-Prescott.

${ }^{26}$ Teste de Wald: Chi2(1) = 3,05 . 
atendidas. Os testes de Stock-Yogo e o teste F rejeitam a hipótese nula de que os instrumentos são fracos apenas nas regressões das colunas (5) e (6). Apenas também para os resultados mostrados nessas mesmas colunas, não se rejeita a hipótese de que a soma dos coeficientes da expectativa de inflação e a inflação defasada seja igual à unidade.

\section{Conclusões}

Este artigo estimou a curva de Phillips novo-Keynesiana (NKPC) para o Brasil, com dados mensais, para o período janeiro de 2002 à março de 2012. Adicionalmente, para verificar a estabilidade dos resultados, foi estimada uma versão da NKPC para o período janeiro de 1995 a março de 2012. De maneira geral, nossos resultados sugerem que, no período recente, a curva de Phillips tem dificuldades em representar a dinâmica inflacionária brasileira. Em particular, o efeito do custo marginal das empresas sobre a inflação depende da proxy adotada.

Do ponto de vista econométrico, em decorrência de problemas de especificação detectados na estimação pelo método de variável instrumental, tais como a presença de heterocedasticidade e autocorrelação, pudemos verificar a inadequação dessa metodologia. Em seu lugar, aplicamos o método GMMHAC onde ambos os problemas são considerados. Uma investigação minuciosa, com intuito de checar a robustez dos resultados, incluiu também estimar a NKPC usando diferentes proxies para representar as variáveis de interesse. Sendo assim, utilizamos diferentes conjuntos de dados para representar a inflação, a expectativa de inflação, o custo marginal das empresas e o choque de oferta.

Este trabalho sugere certa sensibilidade da curva de Phillips com relação às proxies utilizadas. Notamos que um único resultado permaneceu robusto às diversas mudanças: a expectativa futura de inflação e a inflação passada têm relevância na dinâmica do processo inflacionário. Contudo, o papel das expectativas parece aumentar no período mais recente a partir de 2002. Quando a amostra se estende com dados a partir de 1995, o efeito das expectativas é menor ou semelhante ao da inércia inflacionária. Além disso, para a maior parte das regressões estimadas, não foi possível rejeitar a hipótese derivada da forma estrutural da NKCP, de que a soma dos coeficientes da inflação passada e da expectativa de inflação seja igual à unidade.

Em relação ao aumento do efeito da expectativa de inflação quando usamos dados a partir do início de 2002, isso pode indicar que os agentes econômicos estão focando mais na credibilidade da política monetária gerenciada pelo Banco Central visto que essa datação marca o início do processo de eleição presidencial de 2002 e o consequente começo da era Lula marcada inicialmente por um clima de expectativa quanto às novas diretrizes econômicas a serem seguidas. Seguindo este raciocínio, podemos dizer que os agentes focam menos no que aconteceu no passado para dar mais ênfase à nova forma de como vai ser gerida a política monetária e fiscal.

Com relação ao desemprego, seu impacto de curto prazo sobre a inflação depende do conjunto de proxies adotadas. Contudo, na maior parte dos casos onde as tais variáveis foram usadas, essa relação foi observada com efeito negativo tal como esperado. Já no longo prazo, esse efeito torna-se difícil de ser captado, dando a impressão de ser nulo ou pouco relevante na formação 


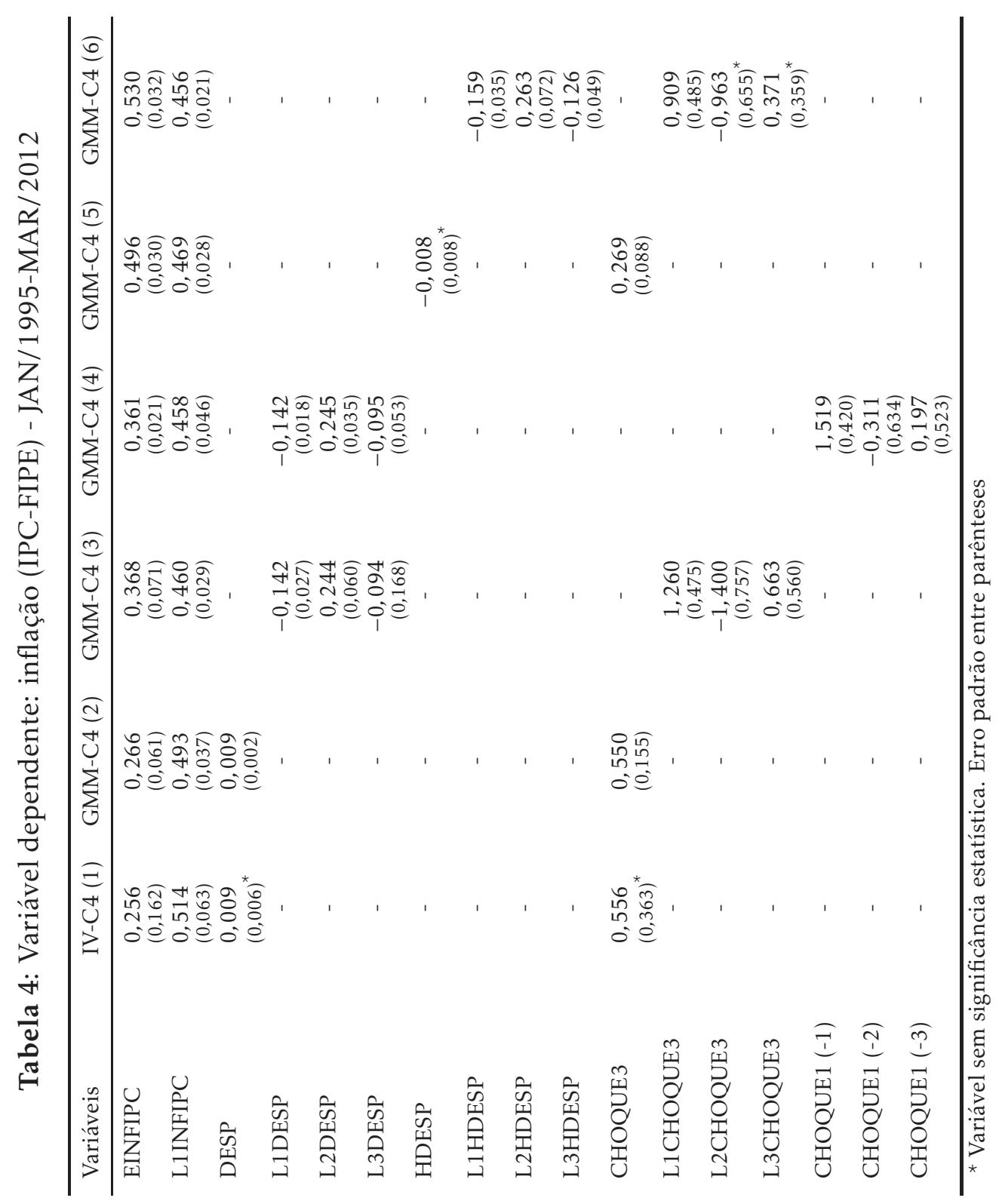




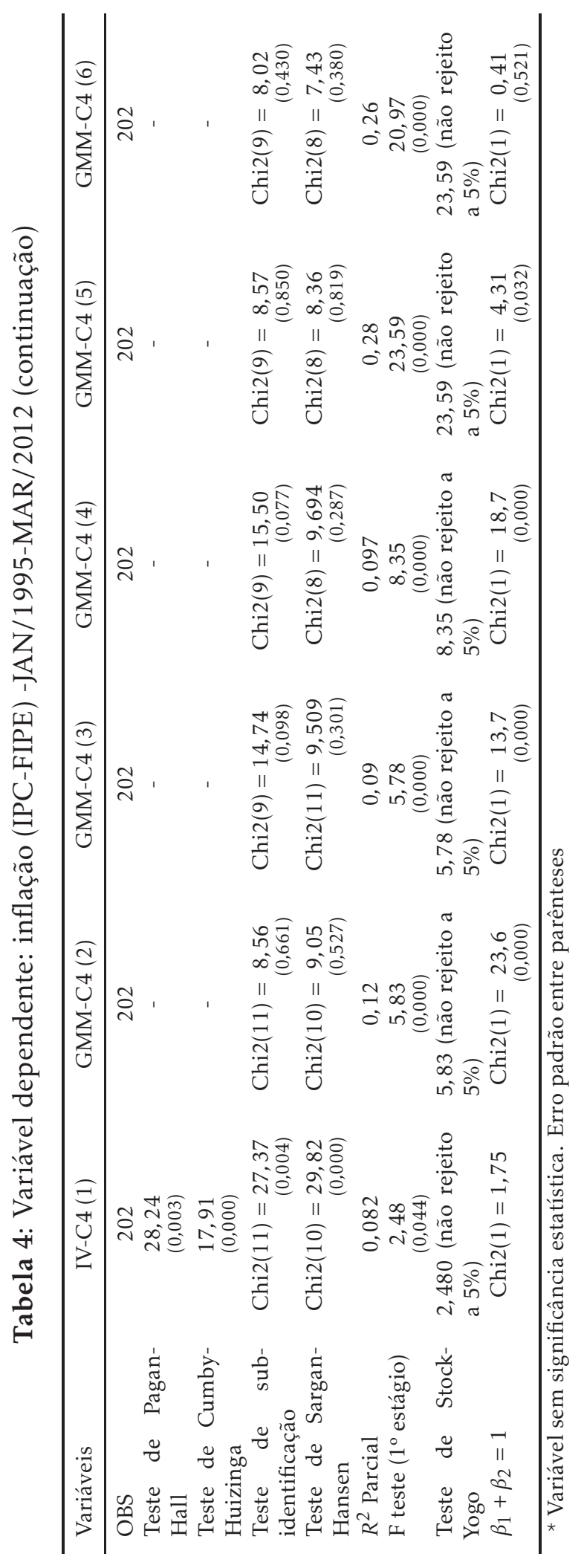


do processo inflacionário. De qualquer forma, em qualquer um dos casos, o efeito real da taxa de desemprego sobre a inflação é próximo de zero. Cabe ressaltar também que, tal como descrito por Estevão \& Carvalho Filho (2012), a economia brasileira passou por importantes mudanças estruturais no período analisado; mudanças essas que podem ter afetado a dinâmica tanto da taxa de desemprego, como da relação desta com os salários reais da economia.

Sobre a relação entre inflação e taxa de câmbio, parece haver uma mudança estrutural no efeito de uma mudança do câmbio sobre a inflação. Com dados a partir de 2002, o efeito de um choque cambial é negativo. Contudo, com a amostra ampliada desde 1995, o efeito de uma desvalorização cambial é positivo sobre a inflação. Novamente, tais resultados são sensíveis às proxies utilizadas.

Com os parágrafos acima em mente, tendemos a concluir que o processo inflacionário brasileiro não guarda relação próxima com a NKPC. Entre os possíveis motivos que explicariam a não adequação da NKPC aos dados da economia brasileira, poderíamos ressaltar os seguintes, primeiro, seria um problema a medição da taxa de desemprego agregando dados das zonas metropolitanas? Acreditamos que não. Sachsida (2009) estimou a NKPC, empregando dados em painel para seis regiões metropolitanas, não encontrando qualquer efeito significativo para a taxa de desemprego na inflação. Segundo, também pode ser que a taxa de desemprego não seja uma boa variável proxy para os custos marginais das firmas. De fato, não podemos garantir isso. Alguns estudos sugerem que uma alternativa melhor seria usar a participação do fator trabalho na renda. Entretanto não existe qualquer estimativa oficial desta série para a economia brasileira. Terceiro, é também possível que erros de mensuração causem viés nas estimativas do efeito da proxy para os custos marginais.

Por fim, pode ser ainda o caso de que a própria estrutura teórica da NKPC esteja em conflito com o que de fato acontece. Sendo assim, faz-se necessário a utilização de outros modelos para tentar replicar a dinâmica inflacionária no Brasil. Isso é de especial importância, dado que a grande maioria dos "macromodelos" para a economia brasileira assumem formatos parecidos com o sugerido pela NKPC para descrever a inflação.

\section{Referências Bibliográficas}

Allsopp, C., Kara, A. \& Nelson, E. (2006), 'Uk inflation target and exchange rate', Federal Reserve Bank of St. Louis Working Paper.

URL: http://research.stlouisfed.org/wp/2006/2006-030.pdf

Alves, S. A. L. \& Areosa, W. D. (2005), 'Targets and inflation dynamics', Central Bank of Brazil Working Paper Series (100).

Andrews, D. W. K. \& Stock, J. H. (2005), Identification and Inference for Econometric Models: Essays in Honor of Thomas Rothenberg, Cambridge University Press.

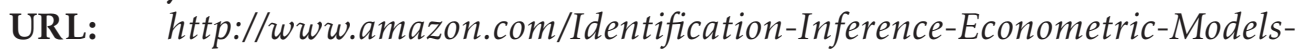
Rothenberg/dp/052115474X\%3FSubscriptionId\%3D0JYN1NVW651 KCA56C102\%26tag\%3Dtechkie-20\%26linkCode\%3Dxm2\%26camp\%3D2025\%26creative\%3D165953\%26creativeASIN\%3D052115474X 
Andrews, W. K. D., Moreira, M. J. \& Stock, J. H. (2006), 'Optimal two-sided invariant similar tests for instrumental variables regression', Econometrica 74(3), 715-752.

Araujo, C. H. V. amd Areosa, M. B. M. \& e Guillén, O. T. C. (2004), Estimating potential output and the output gap for brazil, in 'Anais do XXXII Encontro Nacional de Economia - ANPEC'.

Areosa, W. D., McAleer, M. \& Medeiros, M. C. (2011), 'Moment-based estimation of smooth transition regression models with endogenous variables', Journal of Econometrics 165(1), 100-111.

URL: http://www.sciencedirect.com/science/article/pii/S0304407611001011

Areosa, W. D. \& Medeiros, M. (2007), 'Inflation dynamics in brazil: The case of a small open economy', Brazilian Review of Econometrics 27(1), 131-166.

Arruda, E. F., Ferreira, R. T. \& Castelar, I. (2008), Modelos lineares e não lineares da curva de phillips para previsão da taxa de inflação no brasil, in 'Anais do XXXVI Encontro Nacional de Economia - ANPEC'.

Bardsen, G., Jansen, E. S. \& Nymoen, R. (2004), 'Econometric evaluation of the new keynesian phillips curve', Oxford Bulletin of Economics and Statistics 66, 671-686.

URL: $h t t p: / / d x$. doi.org/10.1111/j.1468-0084.2004.00097.x

Baum, C. F., Schaeffer, M. \& Stillman, S. (2007), Enhanced routines for instrumental variables/gmm estimation and testing, in 'Boston College Economics Working Paper', number 667, Boston College Working Papers in Economics. URL: $h t t p: / / i d e a s . r e p e c . o r g / p / b o c / b o c o e c / 667 . h t m l$

Blanchard, O. \& Galí, J. (2007), 'Real wage rigidities and the new keynesian model', Journal of Money, Credit and Banking 39(s1), 35-65.

Bound, J., Jaeger, D. A. \& Baker, R. M. (1995), 'Problems with instrumental variables estimation when the correlation between the instruments and the endogeneous explanatory variable is weak', Journal of the American Statistical Association 90(430), 443-450.

URL: http://www.jstor.org/stable/2291055

Clarida, R., Gali, J. \& Gertler, M. (1999), 'The science of monetary policy: A new keynesian perspective', Journal of Economic Literature 37(4), 1661-1707. URL: $h t t p: / / w w w . a e a w e b . o r g / a r t i c l e s . p h p ? d o i=10.1257 / j e l .37 .4 .1661$

Correa, A. S. \& Minella, A. (2005), 'Mecanismos não-lineares de repasse cambial: Um modelo de curva de phillips com threshold pra o brasil', Anais do XXXIII Encontro Nacional de Economia - ANPEC.

Cragg, J. G. \& Donald, S. G. (1993), 'Testing identifiability and specification in instrumental variables models', Econometric Theory 9(2), 222-240.

Cumby, R. E. \& Huizinga, J. (1992), 'Testing the autocorrelation structure of disturbances in ordinary least squares and instrumental variables regressions', Econometrica 60(1), 185-195.

URL: http://ideas.repec.org/a/ecm/emetrp/v60y1992i1p185-95.html 
Estevão, M. \& Carvalho Filho, I. (2012), 'Institutions, informality, and wage flexibility: Evidence from brazil', IMF Working Paper.

Fasolo, A. M. \& Portugal, M. S. (2004), 'Imperfect rationality and inflationary inertia: A new estimation of the phillips curve for brazil', Estudos Econômicos 34(4), 725-776.

URL: $\quad h t t p: / / w w w . s c i e l o . b r / s c i e l o . p h p ? s c r i p t=s c i \_a r t t e x t E$ pid=S010141612004000400004 Enrm=iso

Galí, J. \& Gertler, M. (1999), 'Inflation dynamics: A structural econometric analysis', Journal of Monetary Economics 44(2), 195-222.

URL: http://ideas.repec.org/a/eee/moneco/v44y1999i2p195-222.html

Galí, J., Gertler, M. \& Lopez-Salido, J. D. (2001), 'European inflation dynamics', European Economic Review 45(7), 1237-1270.

URL: http://ideas.repec.org/a/eee/eecrev/v45y2001i7p1237-1270.html

Kara, A. \& Nelson, E. (2002), 'The exchange rate and inflation in the uk', Monetary Policy Committee Unit, Bank of England - Discussion Papers.

URL: $h t t p: / / i d e a s . r e p e c . o r g / p / m p c / w p a p e r / 11 . h t m l$

Kleibergen, F. \& Paap, R. (2006), 'Generalized reduced rank tests using the singular value decomposition', Journal of Econometrics 133(1), 97-126.

URL: $h t t p: / / i d e a s . r e p e c . o r g / a / e e e / e c o n o m / v 133 y 2006 i 1 p 97-126 . h t m l$

Lima, E. C. R. (2003), 'The nairu, unemployment and the rate of inflation in brazil', Revista Brasileira de Economia 57(4), 899-930.

Lindé, J. (2005), 'Estimating new-keynesian phillips curves: A full information maximum likelihood approach', Journal of Monetary Economics 52(6), 1135-1149.

URL: http://ideas.repec.org/a/eee/moneco/v52y2005i6p1135-1149.html

Ma, A. (2002), 'Gmm estimation and the new phillips curve', Economic Letters, 76(3), 411-417.

URL: $h t t p: / / w w w . s c i e n c e d i r e c t . c o m / s c i e n c e / a r t i c l e / p i i / S 0165176502000836$

Mazali, A. A. \& Divino, J. A. (2009), 'Real wage rigidity and the new phillips curve: the brazilian case', Catholic University of Brasilia Working Paper.

Minella, A., Freitas, P. S., Goldfajn, I. \& Muinhos, M. K. (2003), 'Inflation targeting in brazil: Constructing credibility under exchange rate volatility', Journal of International Money and Finance 22(7), 1015-1040.

Moreira, M. J. (2003), 'A conditional likelihood test for structural models', Econometrica 71(4), 1027-1048.

Muinhos, M. K. (2004), 'Inflation targeting in an open financially integrated emerging economy: The case of brazil', Estudos Econômicos 34(2), 269-296.

Murray, M. P. (2006), 'Avoiding invalid instruments and coping with weak instruments', Journal of Economic Perspectives 20(4), 111-132.

URL: http://ideas.repec.org/a/aea/jecper/v20y2006i4p111-132.html 
Pagan, A. R. \& Hall, D. (1983), 'Diagnostic tests as residual analysis', Econometric Reviews 2(2), 159-218.

URL: $h t t p: / / w w w . t a n d f o n l i n e . c o m / d o i / a b s / 10.1080 / 07311768308800039$

Portugal, M. S., Madalozzo, R. C. \& Hilllbrecht, R. O. (1999), nflation, unemployment and monetary policy in brazil, in 'Encontro Brasileiro de Econometria - SBE'.

Rudd, J. \& Whelan, K. (2005), 'New tests of the new keynesian phillips curve', Journal of Monetary Economics 52(6), 1167-1181.

URL: http://ideas.repec.org/a/eee/moneco/v52y2005i6p1167-1181.html

Sachsida, A. (2009), 'Reexaminando a curva de phillips brasileira com dados de seis regiões metropolitanas', Texto para Discussão do IPEA.

Samuelson, P. \& Solow, R. M. (1960), 'Analytical aspects of anti-inflation policy', American Economic Review Papers and Proceedings 50(2), 177-194.

Schwartzman, F. F. (2006), 'Estimativa de curva de phillips para o brasil com preços desagregados', Economia Aplicada 10(1), 137-155.

URL: $\quad h t t p: / / w w w . s c i e l o . b r / s c i e l o . p h p ? s c r i p t=s c i \_a r t t e x t E$ pid=S141380502006000100008 Enrm $=$ iso

Shea, J. (1997), 'Instrument relevance in multivariate linear models: A simple measure', Review of Economics and Statistics 79(2), 348-352.

Sims, C. A. (1992), 'Interpreting the macroeconomic time series facts: The effects of monetary policy', European Economic Review 36(5), 975-1000.

URL: $h t t p: / / i d e a s . r e p e c . o r g / a / e e e / e e c r e v / v 36 y 1992 i 5 p 975-1000 . h t m l$

Stock, J. H., Wright, J. H. \& Yogo, M. (2002), 'A survey of weak instruments and weak identification in generalized method of moments', Journal of Business E Economic Statistics 20(4), 518-29.

URL: $h t t p: / / a m s t a t . t a n d f o n l i n e . c o m / d o i / a b s / 10.1198 / 073500102288618658$

Stock, J. H. \& Yogo, M. (2005), Testing for Weak Instruments in Linear IV Regression. In Identification and Inference for Econometric Models, Cambridge University Press, chapter Essays in Honor of Thomas Rothenberg, p. 80-108.

Svensson, L. E. O. (2000), 'Open-economy inflation targeting', Journal of International Economics 50(1), 155-183.

URL: $h t t p: / / w w w . s c i e n c e d i r e c t . c o m / s c i e n c e / a r t i c l e / p i i / S 0022199698000786$

Tombini, A. A. \& Alves, S. A. L. (2006), 'The recent brazilian disinflation process and costs', Central Bank of Brazil Working Paper Series, n. 109. 
Apêndice A Estatísticas Descritivas das Variáveis

Tabela A.1: Período: jan/2002 a mar/2012

\begin{tabular}{lrcrr}
\hline Variável & Média & Desvio Padrão & MAX & MIN \\
\hline INFIPCA & 0,530 & 4,11 & $-0,21$ & 3,02 \\
INFIPC & 0,466 & 0,437 & $-0,31$ & 2,65 \\
NUCLEO1 & 0,521 & 0,283 & 0,06 & 1,71 \\
NUCLEO2 & 0,525 & 0,278 & 0,01 & 1,95 \\
FOCUSMD & 0,443 & 0,169 & 0,14 & 1,95 \\
FOCUS30 & 0,450 & 0,186 & 0,11 & 1,43 \\
DESBRA & 9,185 & 2,201 & 4,70 & 13,12 \\
DESP & 15,661 & 3,117 & 9,00 & 20,70 \\
CHOQUE1 & $-0,001$ & 0,039 & $-0,10$ & 0,19 \\
CHOQUE3 & $-0,006$ & 0,088 & $-0,19$ & 0,34 \\
\hline
\end{tabular}

Obs: Valores referentes às medidas de inflação e desemprego são expressos em termos percentuais (\%).

Tabela A.2: Período: jan/1995 a mar/2012

\begin{tabular}{lrcrr}
\hline Variável & Média & Desvio Padrão & MAX & MIN \\
\hline INFIPC & 0,532 & 0,607 & $-1,00$ & 3,72 \\
DESP & 10,432 & 1,461 & 9,00 & 20,70 \\
CHOQUE1 & 0,004 & 0,042 & $-0,11$ & 0,24 \\
CHOQUE3 & 0,011 & 0,091 & $-0,19$ & 0,47 \\
\hline
\end{tabular}




\section{Apêndice B Gráfico das variáveis}
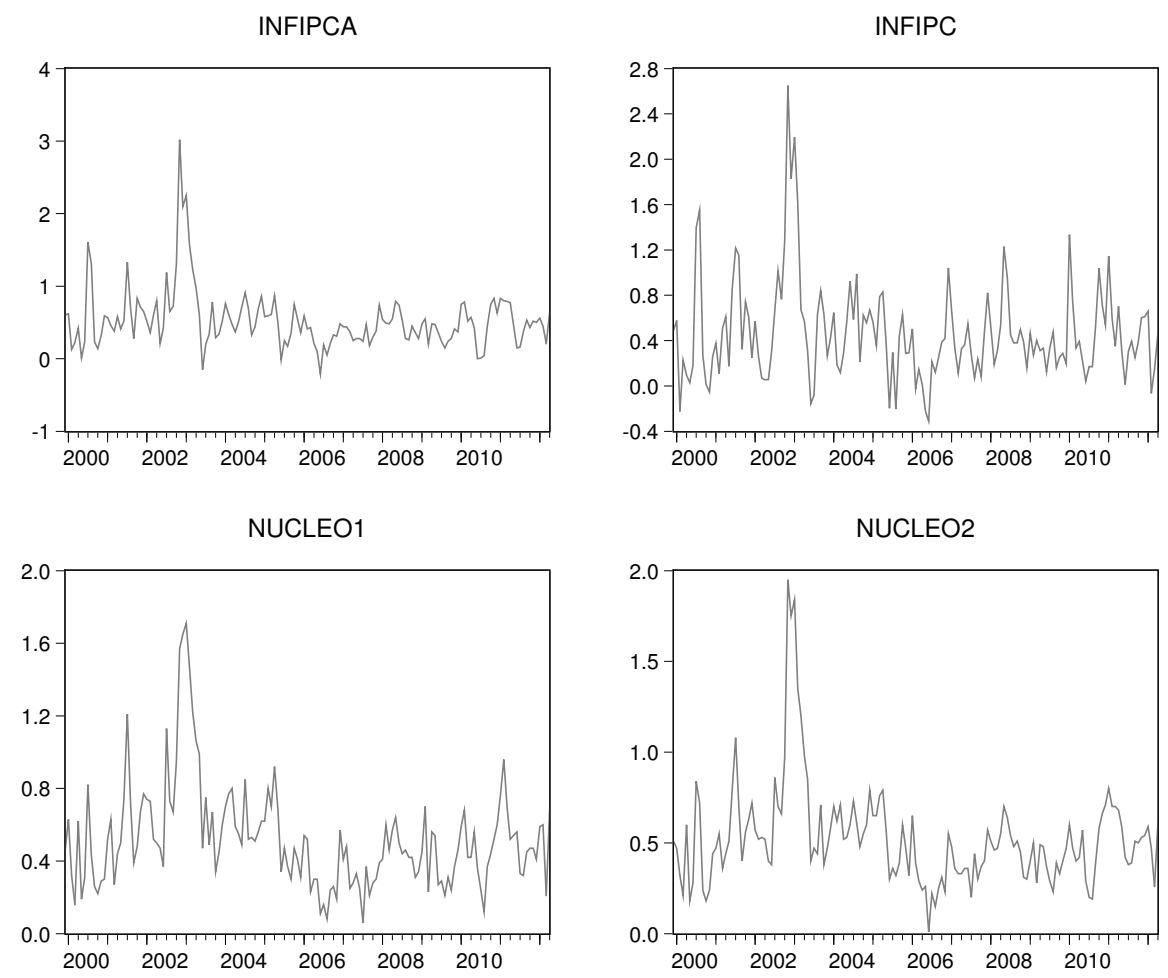

Figura B.1: Proxies para a inflamação 
CHOQUE1
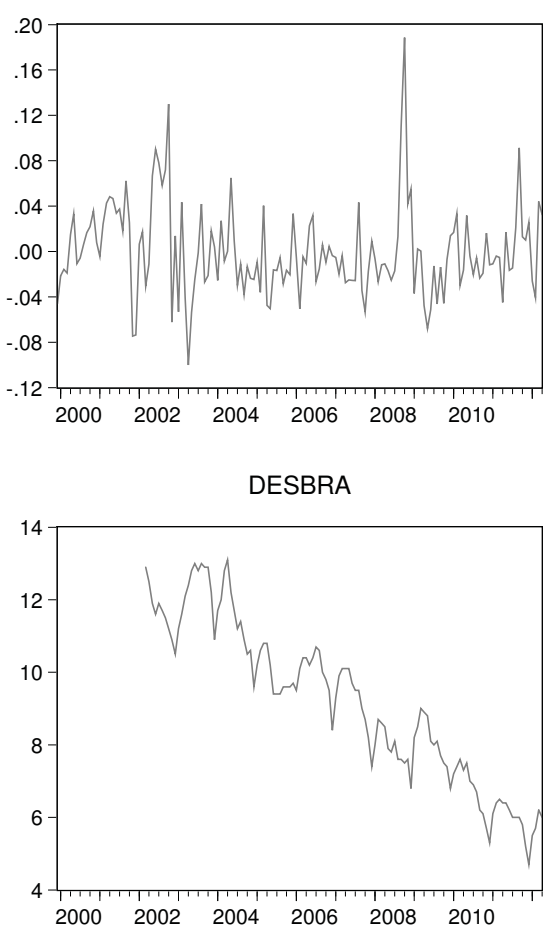

CHOQUE3
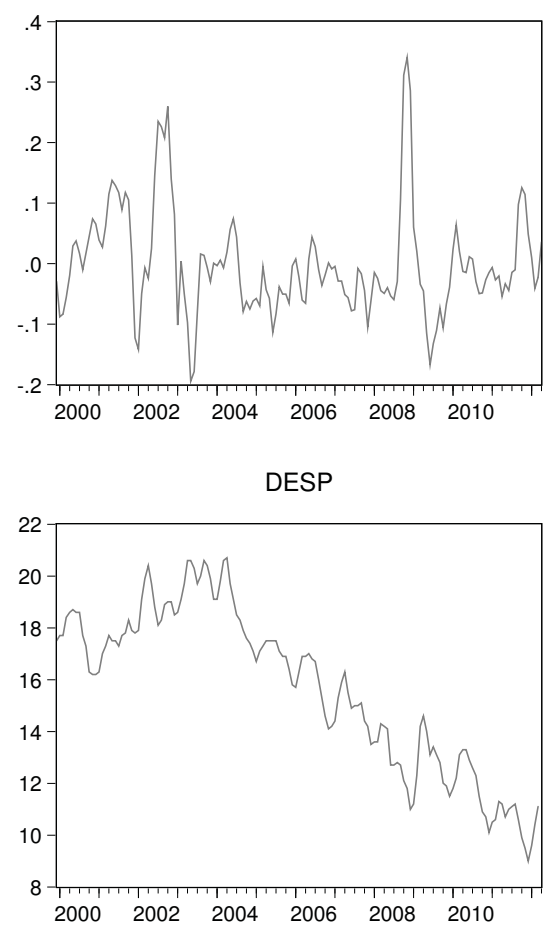

Figura B.2: Proxies para o choque cambial e o desemprego 

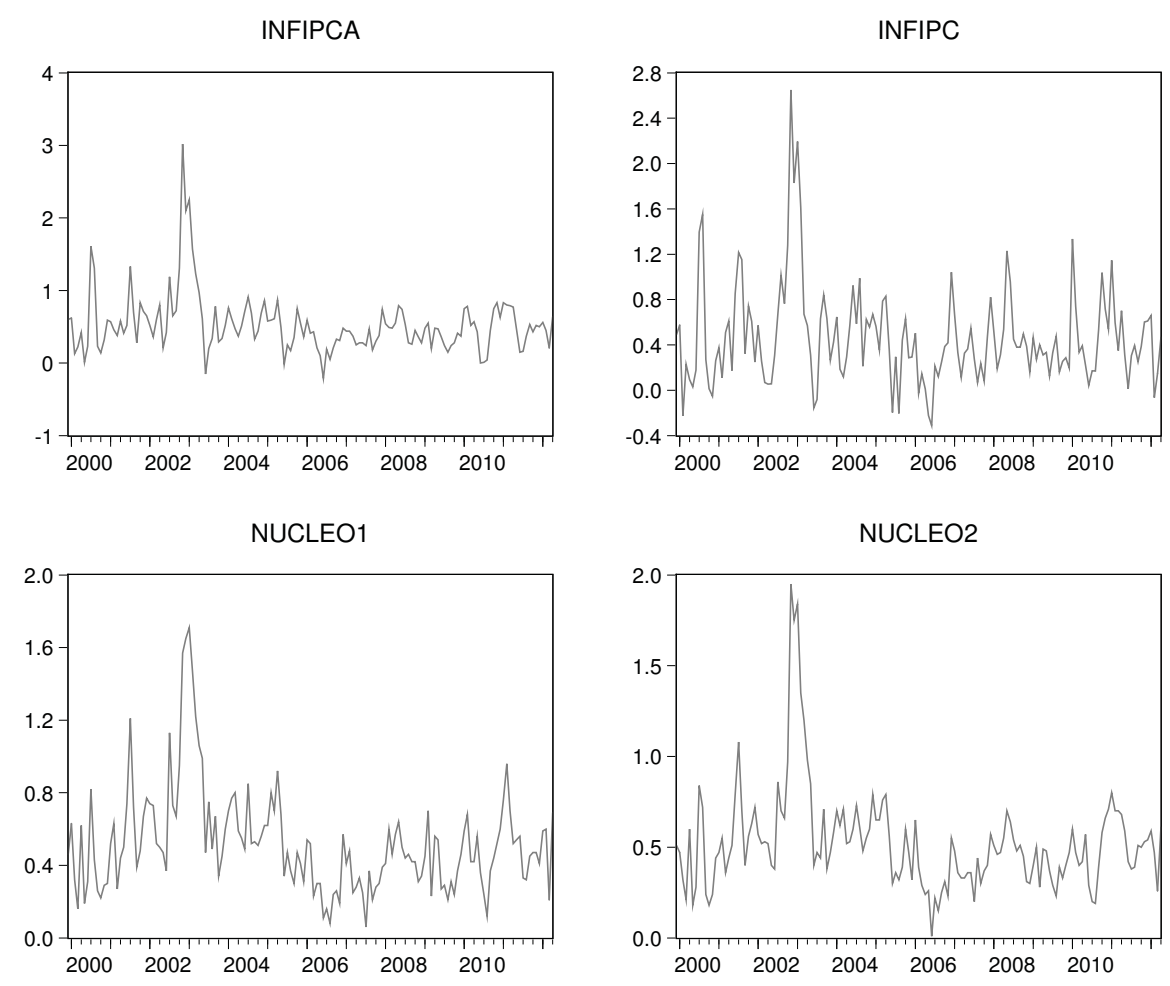

Figura B.3: Proxies para a expectativa de inflação 